\title{
PANOPTISMO ÀS IDENTIDADES EDUCACIONAIS DE PASSAROFES DE UMA ESCOLA DO CAMPO: INADUBAÇÕES SOBRE O ISSO
}

Raoany de Souza Ribeiro ${ }^{1}$ Giseli Monteiro Gagliotto ${ }^{2}$

RESUMO: Objetivamos primeiramente, fomentar o estranhamento/curiosidade nas palavras diferentes no título deste trabalho. Sobretudo, a pretensão central dessa pesquisa é trabalhar o conceito de panoptismo de Foucault, como questões de vigília e controle das identidades de passarofes (palavra que mistura pássaro com professor junto a uma linguagem não-binária) de uma escola do campo, trazendo conceitos como inadubação (não-dito e suas consequências), assim como o isso, referindo-se ao como es passarofes se direcionavam ao falar de lesbianidades. Este artigo então é um recorte de uma das questões abordadas na dissertação de mestrado chamada: Discursos e Não-Discursos do Isso: passarofes de uma escola do campo, inadubações e lesbianidades cis. Utilizamos como diálogo teórico, um artigo produzido anteriormente pelas mesmas autorias, cujo título é: Panoptismo às identidades lésbicas: a escola que vigia, rotula, pune e controla. Percebemos, então, que existem hierarquias de controle e poder dependendo de quem, quando e onde são alvos do panoptismo, neste caso, esses passarofes como um lugar mais privilegiado em relação a alunes, e desprivilegiado em relação à coordenação, diretoria, governo, Estado ou sistema educacional brasileiro. Olhos que se observam e se vigiam a partir de uma escada de privilégios sociais diante de suas identidades e de seus corpos.

Palavras-chave: Panoptismo; identidade; passarofes; lesbianidades cis; escola do campo.

\section{PANOPTISM TO THE EDUCATIONAL IDENTITIES OF PASSAROFES OF A SCHOOL OF THE FIELD: IMPLICATIONS ABOUT IT}

\begin{abstract}
First, we aim to stimulate curiosity on different words/estrangement in the title of this work. Above all, the central claim of this research is to work the concept of Eddy panoptism, as waking issues and identity control birdteachers (Word that mixes bird with teacher with a non-binary language) of a field school, bringing in concepts such as outfert (unsaid and its aftermath), as well as this, referring to as passarofes if the targeted es talk lesbianities. This article then is a cutting from one of the issues addressed in the master's thesis called: Speeches and speeches That: birdteachers a field school, outferts and lesbianities cis. We use as theoretical dialogue, an article produced previously by the same publishers, whose title is: Panoptism at lesbian identities: the school watchman, labels, pune and controls. We realized then that there are hierarchies of control and power depending on who, when and where are panoptism targets, in this case, es passarofes as a privileged place in relation to alunes, and underprivileged with regard to coordination, management,

\footnotetext{
${ }^{1}$ Mestra em Educação pela Universidade Estadual do Oeste do Paraná - UNIOESTE, docente na mesma universidade. Contato: raoanydesouzaribeiro@gmail.com

${ }^{2}$ Pós-Doutora em Psicologia pelo Instituto Universitário da Maia-Portugal, docente adjunto D do Colegiado de Pedagogia e do Programa Pós-Graduação Mestrado em Educação da Universidade Estadual do Oeste do Para UNIOESTE, Campus de Francisco Beltrão. Contato: giseligagliotto@ig.com.
} 
Government, State or Brazilian educational system. Eyes are watching and if they watch from a ladder of social privileges on their identities and their bodies.

Key-words: panoptism; Identity; Birdteachers; lesbianities cis; field school.

\section{INTRODUÇÃO}

Primeiramente a intenção do texto, foi a partir do título, causar estranhamento a quem o fosse ler, afinal como afirma Silva (2003), precisamos falar das diferenças e porque não, de palavras diferentes. Entretanto, o objetivo central é trabalhar questões acerca do conceito panóptico de Michel Foucault (1987) pelo livro Vigiar e Punir, inspirado da torre panóptica de Bentham (2008), utilizando em todo texto um ensaio de uma linguagem nãobinária, sugerida pelo autor (Lau, 2016) ${ }^{3}$.

Este trabalho produz um diálogo com o artigo Panoptismo às identidades lésbicas: a escola que vigia, rotula, pune e controla ${ }^{4}$, ainda, a presente pesquisa se faz também como um recorte de um dos temas produzidos da dissertação de mestrado das autoras, intitulado: Discursos e Não-Discursos do Isso: passarofes de uma escola do campo, inadubações e lesbianidades cis.

Explicando os termos utilizados: o panoptismo, é um fenômeno colocado na pesquisa como o Olho que Tudo Vê (OTV), no intuito de vigiar e controlar os corpos; O termo "passarofes" (pássaro + professor + linguagem não binária + plural $=$ passare + professore + plural $=$ passarofe) surgiu quando a mestranda estava na escola pesquisada realizando entrevistas na sala des passarofes e de forma inesperada, apareceu uma canarinha, nas grades da janela, na sala; foi quando foi percebido, que em todas as entrevistas, es passarinhes faziam canções de fundo, logo teve a ideia de metaforizar o animal com as pessoas, sobretudo, es passarofes pesquisades.

Sobre as inadubações, como não só o conceito de não-discurso de Foucault, mas como todo o processo vivencial, cultural, psicológico, assim como as consequências das consequências (ciclo de não adubações ou inadubações) causadas por não conseguir fertilizar a terra (o ser humano) com o adubo correto a esta terra. Utilizando a comparação metafórica

\footnotetext{
${ }^{3}$ Em sua dissertação de mestrado pelo Programa de Pós-Graduação em Linguagem, Identidade e Subjetividade, referente à linha de pesquisa Subjetividade, Texto e Ensino - defendeu, o impacto da linguagem na cultura e não utilização do X, como "todxs" por não ser possível realizar leituras nem com máquinas específicas para pessoas cegas, e pela dificuldade de pronunciar as junções de duas consoantes para uma fonética que não existe na língua brasileira.

${ }^{4}$ Artigo completo apresentado e publicado em anais do evento: V Simpósio Internacional de Educação Sexual: saberes/trans/versais currículos identitários e pluridades de gênero pelo Centro de Ciências Humanas, Letras e Artes e Departamento de Teoria e Prática da Educação. Universidade Estadual de Maringá (UEM); Processo n ${ }^{\circ}$ 12326/2016; Registro n 088/2017; Folhas 494-503.
} 
em que o Ser humano é terra e passarinho, adubada, inadubada, no chão, voando ou no ninho, com os riscos iminentes de cada espaço, ou microssistema, que no caso desta pesquisa é em uma escola do campo, além de representar um ciclo interrelacional e intrarrelacional. O primeiro quando nos adubam como terra e a gente como passarinhe nos alimentamos dos frutos que dão nessa terra, assim como no segundo caso, quando nos adubamos, nos alimentamos de nossos próprios corpos fertilizados, da melhor maneira possível, ou simplesmente, o seu oposto diante, no caso dessa pesquisa, das lesbianidades cis.

Lesbianidades cis são expressões da sexualidade humana, na qual uma pessoa uma pessoa que nasce com vulva e vagina se identifica com o gênero feminino, colocado culturalmente pela sociedade em que vive, entretanto, também possui sentimentos eróticos com outras mulheres, sendo cis ou não. Lembrando que o oposto de cis é a transexualidade 5 . Vale lembrar que além dessa diferença entre lésbicas cis e lésbicas transexuais, as cis, tem mais privilégios que as trans, por se encaixarem em uma das normas padrões da cultura social mais reproduzida.

Problemáticas e dilemas acerca de formações identitárias des passarofes em relação À temática das lesbianidades cis na escola, principalmente em específico, na escola do campo escolhida.

A seguir será retratado o não dito, não discurso e/ou as inadubações existentes na palavra "isso", colocada nos discursos dos não-discursos nas entrevistas realizadas. Na segunda seção será esmiuçado questões panópticas sobre as identidades educacionais des passarofes sobre a temática das lesbianidades cis. Na terceira seção serão trabalhadas as Inadubações da Escola do Campo com Passarofes Versus a temática das Lesbianidades Cis na Escola do Campo. Neste caso, esperamos que o voo seja prazeroso.

\section{O ISSO: O PIO E O NÃO PIO DE PASSAROFES DO CAMPO}

O medo des responsáveis des passarunes do campo quanto ao tema, como bem lembra Fitz, é importante ressaltar que existe um sentimento de fortalecer identidade, principalmente quando um grupo se encontra em construção ou instabilidade, pontuou sobre a história de colonização gaúcha, que "O isolamento a que os colonos foram submetidos reforçou a criação de um sentimento étnico, cultural e religioso próprio", então, criaram escolas coordenadas por igrejas e desenvolveram uma maneira nova de viver, bem como regras de expressão sexual.

\footnotetext{
${ }^{5}$ Pessoas que nascem com identificações de gênero e corpo, opostas ao que a sociedade impõe diante de sua genitália. (JESUS, 2012).
} 
(FITZ 2011, p. 168). Desta maneira, há uma oscilação constante e inconstante entre dizer e não dizer, fazer ou não fazer, etc.

E o pio do canarinho? Pássaro cantador, ressaltado entre poetas e cantories. Seu canto é cortejado e por sua beleza é muitas vezes caçado, engaiolado e mantido preso para que escutem os reclames de seus sons de passarinho. Sobre a canarinha e seu suposto não pio, que é pouco falada e vista apenas para "esquentar" o macho, ou para reprodução, há quem diga que ela não canta, apenas pia. Pois que raras vezes, acontece sim, de uma fêmea cantar. E ainda, há relatos que esta espécie tem práticas homossexuais e lesbissexuais em alguns casos, em cativeiro ou não.

Diferenciações que aparentemente são antagônicas, mas possuem lógicas de Yin Yang como antagônico, complementares e oscilantes, ultrapassando binarismos de dito e não dito, discurso e não discurso.

\begin{abstract}
A esse tema se liga um outro, segundo o qual todo discurso manifesto repousaria secretamente sobre um já-dito; e que este já-dito não seria simplesmente uma frase já pronunciada, um texto já escrito, mas um "jamais-dito", um discurso sem corpo, uma voz tão silenciosa quanto um sopro, uma escrita que não é senão o vazio de seu próprio rastro. Supõe-se, assim, que tudo que o discurso formula já se encontra articulado nesse meio-silêncio que lhe é prévio, que continua a correr obstinadamente sob ele, mas que ele recobre e faz calar (FOUCAULT, 2008, p.26).
\end{abstract}

O que nos lembra do antagonismo de Tácita e Hermes. Hermes, o Deus ${ }^{6}$ romano, mensageiro de Zeus e de outas Deusas e Deuses, Deus dos comerciantes, dos discursos, da comunicação. Tácita, também de origem romana, Deusa do silêncio e da virtude, Deusa dos lares e fertilizadora de terras, Deusa do campo; seu outro nome também é Lara, do grego, uma ninfa que por informar a traição do Deus Júpiter, tirou-lhe assim, a língua, tornando-a muda (FAUR, 2001, p.46; p.101).

Hermes também nunca se cala? Como Tácita se comunicava depois de perder a língua? O canarinho não cala? A canarinha não canta? "O discurso manifesto não passaria, afinal de contas, da presença repressiva do que ele diz; e esse não-dito seria um vazio minando, do interior, tudo que se diz" (FOUCAULT, 2008, p.26).

O primeiro motivo condena a análise histórica do discurso a ser busca e repetição de uma origem que escapa a toda determinação histórica; o outro a destina a ser interpretação ou escuta de um já-dito que seria, ao mesmo tempo, um não-dito. É

\footnotetext{
${ }^{6}$ Escolhemos colocar a acepção, Deus e Deusa, com letras maiúsculas, mesmo não sendo nome próprio, para em parâmetro de igualdade cultural com o Deus cristão, que também foge a gramática, mas é aceito tanto em textos comuns como científicos desta maneira. Isto também é emancipar e igualizar socialmente.
} 
preciso renunciar a todos esses temas que têm por função garantir a infinita continuidade do discurso e sua secreta presença no jogo de uma ausência sempre reconduzida. É preciso estar pronto para acolher cada momento do discurso em sua irrupção de acontecimentos, nessa pontualidade em que aparece e nessa dispersão temporal que lhe permite ser repetido, sabido, esquecido, transformado, apagado até nos menores traços, escondido bem longe de todos os olhares, na poeira dos livros. Não é preciso remeter o discurso à longínqua presença da origem; é preciso tratá-lo no jogo de sua instância (FOUCAULT, 2008, p.26-29).

'Qualquer semelhança, não é mera coincidência'; este ditado nos serve aqui, pois não nos surpreende - o falante; o comunicador; o honroso e confiante Hermes está na figura masculina, e a Deusa Tácita, ou a ninfa associada à Deusa, sejam virtuosas por ficarem caladas, caso contrário, são obrigadas e severamente punidas ao silêncio, às sombras, a não adubação. Consideradas rainhas dos lares e fertilizadoras da terra e/ou a canarinha somente como procriadora.

A História da Sexualidade I, de Foucault (1988), revela o nascimento do patriarcado em que mulheres teriam que ficar dentro de casa, fertilizando a terra o que antes era sagrado e importante. Agora como uma função subalterna e escrava. Amordaçadas socialmente, pela força do Biopoder e por redes que mais parecem com as pescas predatórias, desiquilibrando as relações e distanciando diferenças ao longo da história. Por estes motivos, talvez, a dificuldade de pronunciar a palavra lesbianidades, como os tabus relacionados ao ser mulher e a sua lesbissexualidade.

Quadro 1. Respostas des Passarofes para 'O ISSO'

\begin{tabular}{|c|c|}
\hline PASSAROFES & O ISSO \\
\hline Andorinha & "não participei de nada relacionado a isso". \\
\hline Beija-Flor & $\begin{array}{c}\text { "E de alguma forma teve uma época, que com algum intuito, } \\
\text { esconderam isso" }\end{array}$ \\
\hline Bem-Te-Vi & $\begin{array}{c}\text { "Pode servir que com o tempo eu possa assimilar e trabalhar com } \\
\text { isso" }\end{array}$ \\
\hline Canarinha & "Não falo sobre isso, pois não é minha disciplina" \\
\hline Quero-Quero & "isso faz parte da nossa humanidade, vamos se dizer assim" \\
\hline Sabiá & "a questão da escola é respeitar ou não isso" e os pais pensam \\
"ensinar ou não a ser".
\end{tabular}

Fonte: Elaborado pela autora com dados extraídos das entrevistas (2016/2017). 
O Não-dito através dos Dispositivos escolares em que todos se observavam na sala des passarofes como passarofes panópticos ambulantes de si mesmos e dos outros. E mesmo depois das entrevistas com aqueles com mais "coragem", digamos assim. A dúvida des passarofes, era o como fazer uma educação que falasse de sexualidade em uma escola do campo tradicional e ainda, no momento em que estamos passando.

Tanto que Sabiá e Quero-Quero comentaram sobre a "Lei da Mordaça" e o receio que todo esse alvoroço em relação a sexualidade e a liberdade des passarofes. Mas algo unânime, todes mostraram tensão sobre as mudanças trabalhistas, sobre não saber como vai ser as novas normas escolares, tensões em relação a pessoas reacionárias e fanáticas, intolerância política, perseguições institucionais dentre outras situações, principalmente pelo fato da maioria ser PSS. Logo, o medo aparece nos ditos pelos não ditos.

Gralha Azul confirmou as questões de resistência à situações novas propostas com a afirmativa de: "são muito conservadores", relatando que em sua grande maioria eram de religião católica, todavia, algo contraditório, pois mesmo com tanto conservadorismo, existem, segundo ela, muitas famílias não-nucleares, ou não-tradicionais, pois "tem gente que é criado só pelo pai, só pela mãe ou só pela avó”.

E mesmo com esta contradição e dentre outras, es passarofes possuem temores ao pensar em desagradar a comunidade, ainda mais com os projetos de leis vigentes. Exemplo disso a passarofe Quero-Quero falou da seguinte maneira: No sexto ano, como explicar na aula de Artes sobre a mitologia grega, que tem os Deuses, Deuses Nórdicos. É complicado defender isso dentro de uma escola. Então, foi perguntado se já havia visto alguma questão religiosa cristã, como uma oração, por exemplo, logo Quero-Quero respondeu: "Nunca viu nenhuma oração nessa escola, orações e tal[...]Mas na escola urbana já vi, num sistema de áudio, já ouvi rezando Pai Nosso".

Ainda sobre as resistências e o medo de mudança e até mesmo de exaltar identidades que fizeram essa escola do campo ser possível, com muito penar, a Gralha Azul "piou” como se estivesse machucada:

Tinham pinturas da parede que eram do MST e mudaram a pintura. Ninguém conseguiu mudar o painel[...] A interferência política na escola é fortíssima. As pinturas...As mudanças são difíceis[...] Teve uma época que a prefeitura colocou a diretora de direita, arrancou estufa, arrancou painel, fez um terrorismo, perseguição[...] como matar a vontade da mudança.[...]Hoje em dia os professores tem medo. a direita no paraná é muito forte (grifos nossos). 
Em negrito foi uma frase que causou impacto na mestranda enquanto realizava a entrevista, tudo pautado no medo, es passarinhes acabam desistindo de voar, como se tivessem virado passarinhes de cativeiro, acostumados a espaços limitados, a ficarem dependentes de instancias maiores para fazer apenas o que lhe deixam fazer, sendo perseguidos e aterrorizados, quando decidem sair da gaiola do conformismo, neste sentido "Todo sistema de educação é uma maneira política de manter ou de modificar a apropriação dos discursos, com os saberes e os poderes que eles trazem consigo"(FOUCAULT, p.41, 2014).

O que também comove é que Foucault disse esta frase na década de 70, alimentando a disciplina que "é um princípio de controle da produção do discurso. Ela lhe fixa os limites pelo jogo de uma identidade que tem a forma de uma reatualização permanente das regras" (FOUCAULT, p.34, 2014) e acaba que esses passarofes acabam tomando estas disciplinas como suas, como a maneira mais confortável e eficaz de jogar nesse sistema que nos vigia e controla.

\section{PANOPTISMO ÀS IDENTIDADES EDUCACIONAIS DES PASSAROFES EM DIÁLOGO COM O PANOPTISMO ÀS IDENTIDADES DAS LÉSBICAS CIS}

Que o olho veja, sem ser visto [...] (BENTHAM, 2008, p. 91)

O conceito Panóptico possui como significado base: vigiar e punir para fins de controle, que, será articulado com o ensino-aprendizagem de passarofes e passarunes, junto à reflexão crítica de Diretrizes e Parâmetros Educacionais, bem como políticas públicas que compõem a análise do tema.

A escola, no dever da educadora, organizada por interesses do Estado, e o Estado devendo suprir os interesses do povo. Ora, qual governo brasileiro em sua historiografia o fez de fato? Sobretudo, se não seus próprios interesses econômicos, sorrateiros a diretrizes e parâmetros educacionais ainda arcaicos às demandas das diferenças e da fluidez criativa de processos de subjetivação, gêneros e identidades?

É relevante observar que também, se lê o Estado, em sistema patriarcal e não somente como discussões de gêneros e sexualidades, mesmo gênero sendo assunto mais antigo e amplo, o Panoptismo obedece a uma rede reguladora, material e simbólica a partir de aspirações de quem detém o poder, neste caso, o homem em suas representações de controle por intermédio da cultura capitalista. $\mathrm{O}$ sentido desse corpo que detém o poder desempenhou 
maneiras eficazes para o retorno de lucro e retenção deste, mesmo em microssistemas, como escolas. Quanto tempo de nossas vidas, passamos na escola? Mas, afinal, porque pontuamos tanto a sexualidade nestes contextos de controle?

\begin{abstract}
Aqui, a sexualidade interessa não tanto em si mesma, como seria o caso para um sexologista; ela interessa por ser um modo, um caminho, muito importante de experimentar a subjetivação, pelo qual nos subjetivamos como seres de desejo. A sexualidade interessa na medida em que ela funciona, como um grande sistema de interdições, no qual somos levados a falar sobre nós mesmos, em termos de nossos desejos, sucessos e insucessos, e no qual se dão fortes proibições de fazer isso ou aquilo (VEIGA-NETO, 2007, p.80).
\end{abstract}

A escola, então, com certeza é um ótimo negócio para fabricação de mão de obra padronizada para as necessidades de mercado. Para além de apelos simbólicos de monitoramento a essas adolescentes, mas a ideia de eterna vigília de uma moral sem conceitos ou cientificidade, chamada pelos movimentos de mulheres lésbicas de: lesbofobia. A violência com ou sem discurso, ainda é violência, então, essas estudantes lésbicas e jovens, no fervor do desenvolvimento de subjetivação, de prazeres e torturas, processam seus papéis neste grupo, criando identidades como respostas de sujeições e processos de subjetivação, além de expor identidades como rótulos para fins de demarcação social e direitos

\footnotetext{
Se devemos nos posicionar em relação à questão da identidade, temos que partir do fato de que somos seres únicos. Mas as relações que devemos estabelecer conosco mesmos não são relações de identidade, elas devem ser antes relações de diferenciação, de criação, de inovação. É muito chato ser sempre o mesmo. Nós não devemos excluir a identidade se é pelo viés da identidade que as pessoas encontram seu prazer, mas não devemos considerar essa identidade como uma regra ética universal (FOUCAULT, 2004, p. 266).
}

No livro da pedagoga Melo (2004), logo em seu sumário, revela com objetividade, marcas no processo de identidade e corpo diante de uma intersubjetividade inserida no meio: "o sujeito é sempre um sujeito encarnado, como também o são professores e seus alunos na vivência do cotidiano escolar", ou seja, o "corpo é o seu "modo de Ser no mundo" (p.42).

Diante desses diversos contextos, a escola, como instituição, também é um espaço em que esses corpos habitam, principalmente com as influências políticas, pelo viés da vigília e da punição, assim como prisões e igrejas, através da cultura, a ética e pelas redes de poder, como as políticas na educação (FOUCAULT, 1987). Escrevendo sobre corpo e corporeidade como receptores e atores do exercício do biopoder o passarofe Jacondito (2006) complementa 
não só essas influencias no organismo biológico, mas nas expressões da identidade que se sobressaem no corpo a partir das relações.

Mas, e es passarofes? Qual seria o papel destes, se essa vivência escolar fosse uma orquestra e es passarofes es regentes? passarofes em sua orquestra de ensino-aprendizagem as separam em grupos? Menosprezam o som de seus instrumentos? Desligam o microfone? As obrigam a tocar outros instrumentos que não querem? Escutam suas músicas? Reconhecem e valorizam as músicas, independente de qual ou quais instrumentos musicais escolheram? Ensinam a respeitar a criatividade subjetiva de cada estudante? Reduzem-nas a um rótulo de práticas sexuais? Ou ainda se sentem presos à torre panóptica dos responsáveis, da coordenação, direção, instituição, sistema educacional, Estado que vigia, pune e controla, e ainda, projetam e reproduzem suas desventuras sobre es passarunes?

Já de antemão, foram discutidas também, as questões de padronização de saberes na escola, por aspirações de controlá-lo e coordená-lo, ganhando força com a diminuição do valor de tudo que leve es passarunes e passarofes a pensarem de maneira crítica e intelectual (GIROUX, 1997), enfatiza o desafio docente de transformação das práticas educacionais.

Lésbicas cis, que controladas pelo símbolo da vigília, mesmo que o gênero feminino seja de acordo com o que projetaram para ela desde a infância, por ter nascido com vulva, a inadubação momentânea não apaga a memória das violências que saem dos corpos de quando o assunto emerge, ou de quando algo lesbiano se torna visível; ele por sua vez, o panoptismo nesta configuração, é uma metáfora de percepção e interpretação de símbolos.

Segundo Foucault (1987), Panoptismo, surgiu da reflexão de uma torre, uma das traduções seria como o olho que tudo vê, no sentido da percepção ampla não exatamente da visibilidade do enxergar; assemelha-se inclusive, ao Olho de Sauro ${ }^{7}$, como aquele que sente e percebe o medo, não tão antigo, quanto a lenda do olho de Hórus era Egípcia, sem pálpebras, como onisciência; um saber infalível e eficaz. A história do Egito antigo e também da contemporaneidade, representam símbolos do saber para fins de controle e punição. Então, Foucault (2006) complementa que esse "ser que vigia" com a metáfora do olho em Sócrates, cujo filósofo grego revela esta parte do corpo como o religare, como literalmente os dizeres egípcios retratam, de que os olhos são as "janelas da alma", e ainda, há a afirmativa na mesma obra de Foucault, que segundo Leonardo da Vinci, também são: “espelhos do mundo”. Dessa maneira, como não vigiar para si mesme em meio a tanta vigília?

\footnotetext{
${ }^{7}$ Filme: Senhor dos Anéis - Retorno do Rei (2003).
} 
Quem está submetido a um campo de visibilidade, e sabe disso, retoma por sua conta as limitações do poder; fá-las funcionar espontaneamente sobre si mesmo; inscreve em si a relação de poder na qual ele desempenha simultaneamente os dois papéis; torna-se o princípio de sua própria sujeição. Em conseqüêencia disso mesmo, o poder externo, por seu lado, pode-se aliviar de seus fardos físicos; tende ao incorpóreo; e quanto mais se aproxima desse limite, mais esses efeitos são constantes, profundos, adquiridos em caráter definitivo e continuamente recomeçados: vitória perpétua que evita qualquer defrontamento físico e está sempre decidida por antecipação (FOUCAULT, 1987, p. 226).

Os símbolos de punição e vigília na escola perpassam pela ordem do discurso, na qual contagia tanto com a comunicação excessiva, quanto aquela, cuja língua foi cortada. Para ilustrar tal ponto de vista foucaultiano, iremos metaforizar os mitos de Hermes e Tácita.

Mesmo, Foucault (2006), em A Hermenêutica do Sujeito, seu último curso de 1982, pois dois anos depois veio a falecer, utilizou-se da etimologia da palavra "hermenêutica", como sentido de aprofundamento de si, pois que estamos superficiais. No sentido de que, o sistema se importa com nossos corpos, aquilo que externaliza, não com o sujeito em si, assim como o outro se importa se a menina está com "roupas de menino", age "como menino", e não o que ela sente com isso, como ela está de fato. Sempre, o que é bom, mesmo na filosofia, é referendado no masculino.

Foucault (1988) resgata as funções do corpo da sexualidade e de onde transformou do matriarcado para o patriarcado; justo pela necessidade de se passar as posses ao primogênito, colocando mulheres como "essencialmente" domésticas; cuidadoras do lar e des filhes herdeires. Deste início, guerras ideológicas e materiais tornaram-se mais fortes, e, cada vez mais, os padrões estabelecidos por quem detém o poder, se torna critério de segurança social, bem estar social; ética e valores de família sagrada. Dessa maneira, a preocupação com a procriação e a higiene, ganharam corpos e a sexualidade, tornou-se prática sexual para procriação monogâmica.

O trabalho era essencial, pós-segunda guerra mundial, modernidade, pós-modernidade, o estudo passou a ser deveras importante diante das necessidades econômicas. Para isto, foi acoplada supressão do comportamento sexual considerado pervertido, pois este distrai do foco principal. Tornar-se mão de obra qualificada para o mercado, saudável ou não, e só.

O "sexo" é, pois, não simplesmente aquilo que alguém tem ou uma descrição estática daquilo que alguém é: ele é uma das normas pelas quais o "alguém" simplesmente se torna viável, é aquilo que qualifica um corpo para a vida interior do domínio da inteligibilidade cultural (BUTLER, 2001, p. 155). 
Essa “dinâmica de poder” (BUTLER, 2001, p.155) estão escravizadas “à significação daqueles efeitos materiais", agora o sexo como uma "norma cultural que governa a materialização dos corpos" (IDEM, 2001, p.155), e não algo artificialmente imposto para o gênero, destes processos, desta maneira. Surge às identificações, o repúdio de si, diante daquilo que é colocado não somente pelos discursos, mas por símbolos que circulam em todos os grupos humanos.

Diante desses diversos contextos, a escola, como instituição, também é um espaço em que esses corpos habitam, principalmente com as influências políticas, pelo viés da vigília e da punição, assim como prisões, igrejas etc. (FOUCAULT, 1987). Tais vias reguladoras assombram aspectos da verdade, como certo errado, a moral de si, e a moral do outro (BEAUVOIR, 2005, p. 125).

Com a História da sexualidade, uma "nova fórmula", a saber, emergência do sujeito nas práticas de si. Desta feita, o sujeito se autoconstitui ajudando-se com técnicas de si, no lugar de ser constituído por técnicas de dominação (Poder) ou técnicas discursivas (Saber). Estas técnicas de si são assim definidas: procedimentos que sem dúvida existem em toda civilização, propostos ou prescritos aos indivíduos para fixar sua identidade, mantê-la ou transformá-la em função de determinados fins, e isto graças a relações de domínio de si sobre si ou de conhecimento de si por si (FOUCAULT, 2006, p. 620).

Na pesquisa de Bernardi (1985) a escola é dessexualizada e dessexualizante. Uma vez, que esta instituição admite realizar a Educação Sexual, no entanto, estaria repassando "uma informação desencorajante e enfadonha, acompanhada de normas que visam salvaguardar as instituições" (BERNARDI, 1985, p. 29), de fato, não está. Diante disso, reprovações a essa postura castradora e superficial são tantas e nos fazem perceber o quanto à transversalidade não alcançou os objetivos propostos inicialmente.

E ainda, nos dias atuais (2016 - 2017), surgiram dos movimentos de passarofes através dos sindicatos várias resistências aos projetos de leis que exprimem retrocessos como a Lei da Mordaça, propagada e desenvolvida pela bancada Evangélica e partidos da direita, que tiram a autonomia dos passarofes quanto ao assunto sexualidade; deturpam teorias realizam leituras propositais diante de lentes dogmáticas, para fins de inspeção, em que o Estado aprisiona o passarofe, o passarofe aprisiona e passarune, em um ciclo sem porta de saída, com antigas promessas de "estado novo", mas com a intenção descarada de cortar direitos dos pobres, controlá-los, monitorá-los, puni-los, mas principalmente, que tudo isto seja útil e que recolha lucros, para que a sociedade alcance a felicidade plena. Bentham (2008), o criador da Torre Panóptica estrutural, que - Foucault pega emprestado para 
conceituar o estado de vigília e punição - antes, sofria bullying na escola, como um nerd ${ }^{8}$ não popular de filme americano, cria então: prisões, hospitais e escolas onde possam, por meio de rígida inspeção, alcançar êxito de excelência produtiva. $O$ objetivo do princípio da inspeção é “[...] fazer não que eles suspeitem, mas que eles estejam certos de que seja lá o que fizerem será sabido [...]" (BENTHAM, 2008, p.83).

Ora, pois, tão atual, retirar o poder das pessoas, tirando a autonomia e a criticidade dos fatos, colocando propagandas ideológicas na T.V.; quando à mídia mostra sobre as intenções como reforma do ensino médio, reforma trabalhistas, cortes na saúde, porém, otimização dos atendimentos e cortes de bolsas diversas para pessoas com renda baixa ou sem renda. Como mostram tais notícias? Ou não mostram? Qual seria o papel da escola em função dessa demanda?

Salientamos que, a escola tem como papel principal para com os educandos, quanto à Educação Sexual, a necessidade de fornecer informações que supram essa carência desde a infância, mostrando-a de uma forma clara e objetiva, sem falsos pudores, que problematize não só a respeito da sexualidade, mas da sua saúde em geral, com a finalidade de ajudar a tecerem sua própria identidade sem culpa, vergonha e/ou mal estar, como sujeitos que consigam pensar por si próprios, de forma crítica e social, assim como serem capazes de planejar critérios morais e analisarem seu contexto, combatendo o biocentrismo e ideologias inconstitucionais.

No nosso perceber, o governo capitalista não precisa de sujeitos críticos, e sim de sujeitos com conhecimentos específicos para que trabalhem nas áreas que o mercado de trabalho esteja precisando, para alimentar o sistema capitalista e não o intelecto, e ainda, selecionar os pobres para realizar trabalhos mais braçais e técnicos e os mais ricos, para que sejam os intelectuais, inclusive para que gerem conhecimento para o próprio interesse de aumento do lucro.

As redes normalizadoras; uma delas sendo a escola - padroniza e adoece os processos de subjetividades, causando efeitos devastadores no existir do sujeito. Dificulta o que Foucault (1985) de chama de Epiméleia heautoû ou em latim Cura Sui, ultrapassar esses aspectos de si e ir para além da estética em que o conhece-te a ti mesmo de Platão, escrito no Templo de Delfos, seja não só o saber de si, ou ir a busca da verdade, mas o cuidado de si, esse encontro, estratégias e meios de curar e se proteger das importâncias do biopoder (FOUCAULT, 1985, p.49).

\footnotetext{
${ }^{8}$ Passalune que costuma tirar as maiores notas, gostam de assuntos considerados mais complexos e geralmente são excluídos da turma que estudam, sofrendo represálias por ser diferente.
} 
As redes sociais, por conseguinte, também viraram verdadeiros confessionários de pensamentos, acontecimentos e opiniões sobre as mais diversas ocorrências sociais, mecanismos tecnológicos astutos de vigilância e controle, que fazem o sujeito, voluntariamente emitir relatórios da vida pessoal, crenças e opiniões sobre tudo que é levantado como tema nestes fios condutores de comunicação por vezes crítica, mas em sua maioria alienante, como fábrica de pessoas viciadas num mundo virtual, esquecidas das relações diretas e afetivamente concretas. $\mathrm{O}$ distanciamento, o encarceramento ou isolamento, também faz parte da estratégia panóptica de controle. (FOUCAULT, 1985)

Em oposto a essa frieza ou distanciamento vivencial pelo virtual, existe a busca de si, que vem com a cultura da historiografia, cuja arte é viver e pintar a história do mundo. Sobretudo, a tinta do pincel, da pena, ou da caneta foi e é deturpada, escondida, destruída e moldada a interesses econômicos, principalmente para construir identidades normalizadoras antagônicas, de herói e vilão, forte e fraco, bem e mal, branco e preto, homem e mulher, adulto e criança, heterossexual e homossexual, gay e lésbica, feministas e feministas trans; dentre outras dicotomias limitantes de identidades que se constroem pelo desespero de sobrevivência, para lutas políticas e conquistas de direitos, mas aquilo mais íntimo, o subjetivo, o sentir, o prazer, o desejo; são de possibilidades infinitas. (FOUCAULT, 1985)

Todavia, consideramos que ainda estamos nas migalhas de sentir menos dor, de escolher o "menos pior", de subjugar-se a corpos que machucam passarofes, passarunes, passarulheres (pássare + mulheres), negres e meninas que sentem prazer erótico com outras meninas. Esta Torre Panóptica pode ser derrubada, assim como o muro de Berlim, através de investimentos em pesquisas de campo que abordem estas temáticas, políticas afirmativas para possíveis inclusões de estratégias de ensinos para uma educação emancipatória (FOUCAULT, 1985).

\section{PROCESSOS EDUCATIVOS E SEXUALIDADES}

Processo, da palavra latim procedere, significa avançar, mover adiante, ir à frente (DICIONÁRIO VIRTUAL, 2016), sobre os conceitos rasos que lemos sobre processos educativos, o conceito mais completo que encontramos em um diagrama da Universidade do Oeste de Santa Catarina Programa de Pós-graduação em Educação (PPGED), cuja linha de pesquisa é Processos Educativos: 
desenvolvimento e práticas pedagógicas que se processam em diferentes tempos e espaços educativos, níveis de escolarização e modalidades de educação (PPGED, 2016, site).

Luckesi (1994) afirma que existe uma grande importância sobre os processos educativos, que são, es sujeites dos processos educativos, destacaremos duas categorias, que são: A pessoa que educa e é educada, e a outra pessoa que educa e é educada, seria, por conseguinte, es passarofes e es passarunes. Luckesi (1994, p. 97), acusa que a maioria das pessoas segue o senso comum desta pessoa que educa,

\footnotetext{
Para ser professor no sistema de ensino escolar, basta tomar um certo conteúdo, preparar-se para apresenta-lo ou dirigir o seu estudo; ir para a sala de aula, tomar conta de uma turma e efetivar o ritual da docência: apresentação de conteúdos, controle dos alunos, avaliação de aprendizagem, disciplinamento etc. Ou seja, a atividade de docência tornou-se uma rotina comum, sem que se pergunte se ela implica ou não decisões contínuas, constantes e precisas, a partir de um conhecimento adequado das implicações do processo educativo na sociedade.
}

Dessa maneira, seguindo o mesmo autor pela mesma obra, "se não buscarmos o sentido e o significado crítico, consciente e explícito da ação docente, seguimos o sentido e o significado dominante desse entendimento que se tornou senso comum" (IDEM, p.98). Explica que várias vezes não são exigidas uma formação específica para ministrar certas disciplinas e não ressalta que pode ser um péssimo agente educador, nem bom, mas que esse não terá a responsabilidade e a reflexão ética de seu papel no processo educativo como sujeite que educa "tanto do ponto de vista do compromisso político, quanto do ponto de vista da competência técnica e cientifica, que ela exige" (IBIDEM, p.98).

Lembra-me de uma proposta de reforma para o ensino Médio da LDB, de que uma pessoa com "notório saber" pode ministrar aulas em diversas disciplinas, assim como o "professor com licenciatura poderá fazer complementação pedagógica para dar aula de outra disciplina dentro da sua área de conhecimento" (BRASIL, 2016, site). Existem, também, muitas preocupações de como seria essa "complementação pedagógica".

E quem está no "lugar" de aprender? Luckesi (1994) nomeia como educando, ele questiona como a pessoa que educa percebe estie educande e também critica, relatando que também há uma noção distorcida e sem cientificidade sobre quem é e sujeite que está para aprender. 
passivo. Basta observar uma sala de aula e veremos que, na maior parte das vezes, o professor considera que o aluno deve estar ali para receber as "suas lições" e, depois, no final de uma unidade de ensino, desenvolvê-las em provas e testes exatamente como foram ensinadas, até mesmo nas vírgulas e pontos. Não é que o aluno seja propriamente passivo; mas, segundo o senso comum, deve sê-lo. Em geral, os atos e condutas dos professores dão a entender que eles querem que os alunos sejam passivos, pois os ativos "dão trabalho", seja na disciplina comportamental seja na disciplina intelectual. Usualmente, não se tem tido suficiente cuidado com a produtividade do educando (LUCKESI, 1994, p. 99).

Não es desenvolvem como seres autônomos, que buscam também as respostas, não se desenvolvem pesquisadories. A comunidade acadêmica que estes sujeites não possuem capacidade criativa, assim como habilidades de descobertas. E assim até os dias atuais, pois mesmo no Programa de Mestrado, ainda percebe-se limitações para o reconhecimento das criações autônomas des estudantes.

Bem, nos recusaremos a somente repetir com outras palavras e modelar os conceitos existentes com as problemáticas encontradas. Percebe-se como é verídico as consequências de uma educação não-crítica, não-encorajadora, uma educação decadente, interesseira que nos torna preguiçosos para o ensino-aprendizado. Assim, como, complementaremos, que, ambas as categorias demostradas acima, são compatíveis ao ensino-aprendizagem de maneira que este ser que educa, não detém o conhecimento, nem esse educande tem escuta catita e passiva a tudo. Estas pessoas se aprendem e se ensinam mutuamente todos os dias.

O sufixo ismo sugere um sentido patológico, ou anormalidade aparecendo na Classificação Internacional de Doenças (CID), como Personalidade Patológica, somente em 1973 que a Associação Psiquiátrica América, constatou que a homossexualidade nunca foi doença, dois anos depois, a Associação Americana de Psicologia (APA), também chegou à mesma conclusão.

No Brasil, foi somente da década de 80, mais precisamente em 1985, que o Conselho Federal de Medicina (CFM) deixou de considerar como desvio da personalidade ou um transtorno sexual no CID. Sendo assim, a Organização Mundial de Saúde (OMS), também acatou o entendimento médico acerca da homossexualidade. Depois de passados 14 anos do CFM realizar a retirada da homossexualidade como doença, foi que o Conselho Federal de Psicologia (CFP) pela resolução 01/99, vedou qualquer postura de profissionais de psicologia que prometa cura, considerando antiético para o psicólogo que atenda a homossexualidade como desvio comportamental ou doença.

Sobre a questão da sexualidade, as psicólogas Palma e Levandowski (2008) citaram Miranda (2001) em um breve histórico sobre a sexualidade entre pessoas do mesmo sexo. Averiguaram que a sexualidade sempre existiu, nos quais os primeiros relatos aconteceram 
cerca de 2.500 a.C. a partir da era judaico-cristã que a performance sexual pelo mesmo sexo foi imposta como pecaminosa, diante dispo a medicina no século XIX definiu a orientação homossexual como uma patologia fisiológica, no século XX, surgiu a percepção psicológica, considerando a prática um desvio do desenvolver da sexualidade. Contudo as autoras citam Freud (1917/2007, p. 46) que definiu o homossexualismo, como era chamado na época "uma variedade especial da espécie humana, um terceiro sexo que tem o direito de se situar em pé de igualdade com os outros dois".

\section{INADUBAÇÕES DA ESCOLA DO CAMPO COM PASSAROFES VERSUS A TEMÁTICA DAS LESBIANIDADES CIS NA ESCOLA DO CAMPO}

Utilizaremos a palavra inadubar, primeiro porque se entende que apesar do conceito da palavra visibilidade, não ser só agregada para a percepção visual, a palavra em si, parece contemplar somente as pessoas não cegas. Então, foi pensada uma palavra que abrangesse todos os sentidos e processos psicológicos. Logo, o adubar, serão entendidos por: dar valor, atenção, cuidar, perceber, lembrar, preocupar-se com, entender as especificidades da terra (pessoa-sujeite) para então saber qual adubo utilizar melhor.

O Adubo também será percebido, como o processo crítico-reflexivo sobre o fenômeno de Ensino-Aprendizagem, assim como de um bom manejo dos processos educativos. Pois, se um grupo de pessoas ocupa um terreno, se assentam, manejam a terra, mas não aduba, esta terra perde os nutrientes e corre o risco de sofrer erosão, dependendo do tipo da terra, clima etc. adubar a terra, assim como es sujeites, pode ser uma sugestão eficaz em função dos relacionamentos entre as pessoas do campo, na escola e na comunidade que também faz parte da escolarização e educação como um todo, evitando erosões e desgastes a todes, poeticamente discursando.

Quadro 2. Respostas des Passarofes para as perguntas 9, 10 e 11.

\begin{tabular}{|c|c|c|c|}
\hline PASSAROFES & $\begin{array}{l}\text { 9. SE FOSSE SUA } \\
\text { FILHA/FILHO? }\end{array}$ & $\begin{array}{c}\text { 10. CONHECE } \\
\text { ALGUMA } \\
\text { PASSARUNE } \\
\text { ASSUMIDAMENTE } \\
\text { LÉSBICA? } \\
\end{array}$ & $\begin{array}{l}\text { 11. SE A PASSARUNE } \\
\text { LHE PEDISSE AJUDA? }\end{array}$ \\
\hline Andorinha & $\begin{array}{l}\text { "não sei, acho que ia } \\
\text { tentar orientar né" }\end{array}$ & Não & $\begin{array}{l}\text { "é complicado, também } \\
\text { não sei dizer, o que falta é } \\
\text { um acompanhamento na } \\
\text { escola sobre o assunto" }\end{array}$ \\
\hline
\end{tabular}




\begin{tabular}{|c|c|c|c|}
\hline Beija-Flor & $\begin{array}{l}\text { " vai ter todo meu } \\
\text { apoio, porque eu quero } \\
\text { que meus filhos sejam } \\
\text { felizes" }\end{array}$ & Não & $\begin{array}{l}\text { "Primeiro se aceitar como } \\
\text { é, né, primeiro se aceitar } \\
\text { como é, eu não sei se é } \\
\text { fácil, então deve ter um } \\
\text { apoio familiar, também a } \\
\text { família entender isso como } \\
\text { sendo uma coisa normal, } \\
\text { não criando barreiras, eu } \\
\text { vejo assim" }\end{array}$ \\
\hline Bem-Te-Vi & $\begin{array}{l}\text { "que há muita } \\
\text { discriminação e } \\
\text { preconceito, mas não } \\
\text { restaria outra } \\
\text { saída...é... a não ser } \\
\text { apoiar. Acho que a } \\
\text { felicidade pode está } \\
\text { relacionada com...com } \\
\text { a escolha sexual" }\end{array}$ & Não & $\begin{array}{c}\text { "é uma situação que eu } \\
\text { teria que me preparar } \\
\text { mais" }\end{array}$ \\
\hline Canarinha & "não sei" & Não & $\begin{array}{c}\text { "eu ajudaria, mas não } \\
\text { saberia como" }\end{array}$ \\
\hline Quero-Quero & $\begin{array}{l}\text { "Acho que seria } \\
\text { tranquilo, não teria } \\
\text { problema nenhum" } \\
\text { "teria medo dos } \\
\text { outros" }\end{array}$ & Não & $\begin{array}{l}\text { "Eu acho que seria uma } \\
\text { forma de tentar"[...] "pra } \\
\text { que ela não fique...inibida, } \\
\text { presa" }\end{array}$ \\
\hline Sabiá & $\begin{array}{l}\text { "é complicado, acho } \\
\text { que o estranhamento } \\
\text { seria normal[...] mas } \\
\text { aceitaria, não teria } \\
\text { porque recusar né, a } \\
\text { opção dele ou dela" }\end{array}$ & Não & $\begin{array}{l}\text { "primeiro eu iria } \\
\text { encaminhar para a parte } \\
\text { pedagógica da escola né, } \\
\text { antes de tomar qualquer } \\
\text { medida" }\end{array}$ \\
\hline Trinca-Ferro & $\begin{array}{l}\text { "não sei como eu agiria } \\
\text { se meus filhos fossem } \\
\text { assim, tenho amigos, } \\
\text { adoro eles, mas não } \\
\text { sei" }\end{array}$ & Não & $\begin{array}{l}\text { "eu ia pedir(perguntar), o } \\
\text { que que você quer que eu } \\
\text { faça que eu vou fazer", } \\
\text { "vc quer que eu vá na sua } \\
\text { casa conversar com seus } \\
\text { pais? Dentro da pouca } \\
\text { experiência que a gente } \\
\text { tem né, com carinho, a } \\
\text { experiência vem, eu vou } \\
\text { fazer o que eu poder pra te } \\
\text { ajudar, eu não vou tentar } \\
\text { desfazer dela[...]" }\end{array}$ \\
\hline
\end{tabular}

Fonte: Elaborado pela autora com dados extraídos das entrevistas (2016/2017).

As respostas dos passarofes foram diversas, umas dizendo que iria apoiar, mas que é complicado, outros não saberia exatamente o que fazer. Não à toa que por falta de conhecimento, os familiares dessas adolescentes que estão descobrindo suas lesbianidades, 
não conseguem lidar facilmente com a questão. As autoras Palma e Levandowski (2008), Piason (2008), Palma, e Palma (2011), revelam que as primeiras agressões acontecem na família, desde a fase em que reconhecem o sexo biológico da criança, os responsáveis projetam ideias tradicionais e religiosas de gênero, como o que brincar, que roupa usar, como se comportar, casar com um homem e ter filhos.

Não foram muito diferentes quando responderam se iriam ajudar alguma passarune que resolvesse falar sobre seus sentimentos ou práticas lesbianas, também ressaltaram que tentariam ajudar, mas que não estão preparados para isto, etc. Mas, sobre o que eles pensam que seja essa sexualidade, e o que é cientificamente escrevendo, existe distanciamentos de ações, que se treinades para atender essa demanda, poderiam fazê-la com mais segurança e melhor eficácia.

Quando aqui é falado de teoria, também é considerado o seu oposto, que seriam os achismos. Neste sentido, o que se mistura com valores e teorias nas práticas desses profissionais da educação em relação às lesbianidades?

Como todos, o profissional da escola se adapta às posturas novas do cotidiano sem muito espaço de crítica. Passivamente ele assiste TV, lê revistas e jornais, frequenta bares, clubes, mas na escola e esse é o ponto intrigante, ele assume o papel repressor sendo defensivo contra mudanças, omitindo-se aos fatos que podem sua participação como um educador sexual (GUIMARÃES,1995, p.18).

Beija-Flor e Trinca-Ferro, as passarofes com mais idade diante des entrevistades, foram as respostas mais precisas, seguras e empáticas que pudemos analisar, Beija-Flor já em período de aposentar-se com 30 anos de experiência e Trinca-Ferro com 10 anos de Docência e apenas com um ano de diferença de idade, demostraram maiores soluções em relação aos outres, ambas com categorias semelhantes de filhos, casamento, religião, idade etc pareceu que diante a suas várias vivências com as diversidades humanas, lhes fizerem imaginar uma maneira de resolver os conflitos com mais facilidade que es outres, mesmo sendo uma situação que nunca havia lhes acontecido.

Es outres passarores, procurariam ajudar, as adimitiram precisar de melhor orientação, procurando assim, ajuda da coordenação pedagógica e/ou diretoria. Percebe-se nessas relações o pouco diálogo sobre sexo e outras expressões da sexualidade com es passarofes. Então para quem essies passarunes e reportam?

Com quem então, eles falam de sexo? Com os amigos, seus pares. O amigo íntimo é a figura preferida para "tirar dúvidas" sobre sexo, e os amigos em geral servem para 
conversações abertas, os irmãos mais velhos, tios, avós e namorado socorrem em crises. A mãe informa as principais indagações sobre a reprodução e o pai é ausente nessas questões para a maioria absoluta (GUIMARÃES,1995, p.20).

E por qual motivo falamos de sexo e sexualidade? Foucault trabalha não exatamente com a questão do ato sexual e sim com os dispositivos de poder que permeiam o ato sexual, sobre onde fazer, quando fazer, com quem fazer, como fazer incluindo a negativa dessas afirmativas, sobre onde não fazer, quando não fazer, com quem não fazer, como não fazer; sendo essas prerrogativas todas pautadas à interesses econômicos nos quais um grupo, uma elite compõe modelos, padrões e normas a serem seguidos de maneira inquestionada, então, quem tem o poder, domina os prazeres, incluindo o sexo. Lembrando que namoro, casamento, relacionamento, inclui em sua maior parte, o ato. Então, quando falamos de lesbianidades na adolescência, ou em uma escola do campo, também falamos de sexo lésbico, de contraceptivos lésbicos, de leis que amparem a não-violência contra esse grupo de pessoas. Mas em oposto disso, há extensa repressão sexual através da ausência de leis, ausência de diálogo familiar, dentre outras tantas ausências (inadubações).

\begin{abstract}
Reich $(1971,1983)$ une a essa crítica os fundamentos da psicanálise, afirmando que na estreita ligação entre família e economia está a explicação da ampla repressão sexual e submissão ao domínio de autoritarismo político de seu tempo. Para ele, a regulação da vida sexual pelo sistema patriarcal, o elogio à prole numerosa, reforçam as estruturas familiares que reprimem as forças da libido através do enraizamento, a nível psicológico profundo, do sentimento de culpa. Acredita que, diminuindo a autoconsciência individual, formando traços de caráter rígidos, o fascismo impôs o desenvolvimento de idéias reacionárias de dever e honra, de coragem, de autocontrole, de compromisso cego e emocional com a pátria. Propõe que, se o homem recuperasse a lei natural da sexualidade, ele recuperaria tanto a existência prazerosa perdida pela cultura, como sua emancipação social, política e econômica (GUIMARÃES,1995, p.37).
\end{abstract}

Guimarães trabalha com algumas concepções de Reich, no qual percebe que naturalmente o ser humano é poligâmico, ou seja, possui naturalmente a possibilidade de desejar várias pessoas, uma de cada vez ou ao mesmo tempo. Mas a cultura cria regras como freios de conduta. "A contradição natureza e cultura fica mascarada pelo fenômeno da massificação, que forja uma opinião pública coletiva, controlando as mais íntimas necessidades humanas, através do poderio tecnológico". (GUIMARÃES,1995, p.38)Ressaltamos aqui também, a influencia das grandes redes de propagação de controle como: "os livros, os jornais, a mídia tecnológica, invadem a introspecção humana de modo que a esfera pública (o outro) hoje se confunde com a privada ( o eu)" (GUIMARÃES,1995, p.41) 
Um exemplo nessa escola do campo, a passarofe Quero-Quero nos conta uma situação que aconteceu no período de festa junina:

“A festa junina, tudo bem que é uma questão cultural, a gente tá trabalhando e...música tradicionais[...]mas ainda há... ainda tudo isso tem que ser o parzinho, menino e menina, por conta dos próprios profes dizendo: 'não tu não pode ter, é... do mesmo sexo misturado, ...eles não podiam se escolherem, tinha que ser, os parzinhos, os casaiszinhos". Quem escolheu foi a professora. "Tinha professora que cobrava bastante".

Quando Quero-Quero foi perguntada se tinha alguma menina que quis fazer com alguma amiga, ela respondeu que "Tinha porque se sentia mais a vontade também" e ainda completou:

\footnotetext{
"foi unidos vários turmas, então, por exemplo, teve bem mais...no Ensino Médio, dois meninos apenas, do Ensino Médio dançaram, alguns não puderem porque estavam nos jogos no dia, mas todo restante, só dois que foram, então, era tudo entre meninas mesmo, elas se sentiram mais a vontade de fazer uma dança associada à isso, mas no fundamental foi imposto, tem que ser e os que não queriam, acabaram ficando sem ir dançar".[...]Teve um caso no fundamental de dois meninos que queriam dançar juntos, não chegaram a se apresentar, porque eles queriam ficar brincando nos ensaios, não estavam levando a sério. Não teve tempo pra amadurecer a situação, não estavam rendendo.[...]Músicas trabalhadas: Rio Negro e Solimões e músicas country. [...]Ensino Médio tiveram mais autonomia, Sharaia...(Shania Twain - Any Man Of Mine)sei lá. Não quiseram dançar Xote. As meninas propuseram envolver o Country, depois colocaram a música de Rio Negro e Solimões.
}

Essa imposições das quais Quero-Quero fala, são como já foram comentadas, reproduções do que o sistema de poder nos oferece, tratando a sexualidade como um mal, ou uma doença contagiosa, principalmente quando se trata de criança e adolescente. Sexualidade essas que são expressas nas danças e socialmente aceitas pela comunidade escolar e pelies responsáveis que não perceberam que a tradução dessa dança Country de cunho feminista, iniciando a letra com: "isto é o que uma mulher deseja... qualquer homem meu, é melhor que tenha orgulho de mim, mesmo quando estiver horrível, é melhor que ele ainda me ame...", isso tudo é a expressão da sexualidade velada.

A sexualidade humana se explica pela natureza e cultura e pode ser compreendida tanto em sua evidência objetiva, manifestada no social, como na realidade subjetiva, experimentada internamente pelo ser humano. [...] O local onde a natureza e a cultura se encontram em estado primeiro é a família e nela a moldagem cultural da natureza intensa (GUIMARÃES,1995, p.29 grifo nosso). 
A família aceitaria, assim como aceitou, que as passarunes dançassem essa música, tanto que houve conseguiram-se as roupas e não é como uma escola urbana em que é mais fácil esconder alguns eventos da escola des responsáveis e podemos nos perguntar, por quais motivos uma menina se sentiria mais a vontade dançando com outra menina. $\mathrm{O}$ que pode representar um par masculino em uma dança que fala de relacionamento amoroso heterossexual? O que esse masculino simboliza, de maneira a reprimir uma adolescente a não querer sua companhia em uma dança?

Será que de fato não existem diferenças de gênero? Será que esse assunto não é importante a ponto de causar certos desconfortos e até confrontos relacionais, nas quais meninas não se sentem a vontade na presença de meninos quando se colocam em situações de toque, como uma dança mais próxima, por exemplo? Existe essa sobreposição do mito do macho superior.

Foucault fala da sexualidade como sendo uma elaboração histórica, para ele o ato sexual toma sentido no contexto em que ocorre. A divisão dos sexos em classes antagônicas e até hostis e a crença na superioridade masculina, tidas como "fatos naturais" são posturas próprias de uma mentalidade construída culturalmente, mas nem a biologia nem a antropologia as justificam (GUIMAR ÃES, 1995, p.31).

E diríamos, nem a psicologia justifica essas afirmativas condicionadas ao sexismo. Neste mesmo "voo", ocorreu um episódio em que Gralha Azul conta:

\begin{abstract}
tem um episódio muito interessante sobre a sexualidade[...] Ela foi fazer uma oficina pra nós lá e, sobre Diversidade Sexual...os meninos maiores, trataram ela...até de forma desrespeitosa, como se ela fosse uma vagabunda que vai lá falar de sexo. E eles se deram o direito de chegar[...]"se vc passar daquele padrão alí que é permitido, se passar pra lá é prostituta" do oitavo para o nono ano.
\end{abstract}

Gralha azul conta que um dia uma passarofe foi realizar uma oficina e por falar sobre sexo em alguns determinados momentos, es passarunes do fundamental, sentiram-se a vontade de demonstrar afetos erotizados à oficineira. $\mathrm{O}$ que nos deixa em questão, nas diferenças entre Ensino Fundamental e Ensino Médio, pois Andorinha, que é passarofe do Ensino Médio, revelou que de fato, es passarunes desse período são mais agitados, disse que "tudo virava brincadeira, não produz tanto" quanto passarunes do Ensino Médio. Ora, essa agitabilidade em ligação com as transformações identitários e de seus corpos poderiam dar 
bons "frutos" para uma pesquisa de doutorado, afinal, estão no auge das grandes transformações. Trabalhar então, questões da sexualidade, questões de gênero.

Por falar em gênero diante das dúvidas des passarofes sobre o como poderiam trabalhar sexualidade e gênero em uma escola do campo, não é no mínimo intrigante revelar as grandes responsáveis pela agricultura? Criação de gado, fabricação de cerâmicas e tecelagens? Aproveitando, para explicar o que aconteceu depois desta época, conhecida como matriarcal.

Com a repressão sexual, gradativamente vai surgindo a família patriarcal, onde o acúmulo de poder está na geração mais velha masculina, sendo a autoridade centrada no homem, que se apropria tanto da força de trabalho quanto da subjetividade da mulher e dos filhos, que passam a lhe pertencer (GUIMARÃES, 1995, p.33).

E mais uma vez a economia, o ter masculino indo na frente do desejo do ser feminino, partindo de relacionamentos monogâmicos construídos pela espreita da posse das coisas e a mulher como coisa. Por isso, ainda, a dúvida do "this" ou "it".

Também a dicotomia corpo e mente, no ser humano, se acentua, uma vez que os corpos passaram a ser tomados como valor de troca nas uniões ou casamentos, e que agora passam a ter um significado de acordos políticos, econômicos e ideológicos, prioritariamente. (GUIMARÃES, 1995, p.33).

E mesmo em que tudo agora virou institucional, o casamento, a união entre duas pessoas, o dito é colocado com um reforço daquilo que é esperado, sendo assim, o contrário, nem precisaria comentar, pois os prazeres e as normas jogam em conflitos sadomasoquistas, nos acostumando a só saber sobreviver de poucas maneiras já preestabelecidas. E mesmo saindo deste regime, caímos em outro, mas a descoberta da disciplina é a justa maneira de ter uma oportunidade de fazer-se diferente principalmente dessa cultura patriarcal.

Uma cultura patriarcal e autoritária encouraçou o homem contra sua própria natureza interior e contra a miséria exterior ao seu redor. A sujeição de um sexo pelo outro acentuou-se, como dominação e conflito, a partir da família monogâmica. (GUIMARÃES, 1995, p.34).

Desta maneira, a mulher, a mulher lésbica, a transexual, o homem cis gay, ou tudo aquilo que tende a mexer em na identidade sensível de um suposto homem cis heterossexual, é desmerecido, depreciado, escondido, diminuído, não adubado. Gralha Azul confirma 
dizendo que "ou é um assunto que vem como piada", "ou é um assunto que vem com observação preconceituosa", mas que "hoje é bem mais tranquilo". Gralha Azul ainda complemente:

\begin{abstract}
Com as questões da comunidade. Se fosse fazer uma fala. "mulher sozinha"[...].Em vinte anos, só se soube um homem homossexual, mas que era discreto e que não falava que era gay...mas ele era muito querido, ele era muito respeitado[...] Um deputado o chamou de "seu viado filha da puta" mas a comunidade ficou do lado dele, final da década de noventa, prometeu uma monte, e plantaram milho na ponte, porque demorou muito a promessa, o deputado entendeu o recado[...]Depende do tipo de trabalho que a pessoa exerce, daí eles pensam assim: "ele é viado, mas é um bom profissional".
\end{abstract}

Percebe-se que existem algumas histórias soltas sobre LGBTI+, todavia, a atenção da pesquisa, foi trabalhar com o imaginário des entrevistades, já que disseram nunca ter passado por situação de ter uma passarune que se colocasse como lésbica nessa escola do campo. A dúvida sobre essas adubações ou inadubações. Segundo Fairchild e Hayward (1996 apud LEVANDOWSKI; PALMA 2008) A negação da sexualidade, por este pensamento de que a mulher é terna, confunde o pensamento social do verdadeiro desejo que algumas mulheres sentem por outras mulheres, acontece que, pelies autories, muitas vezes, as lésbicas, por medo, assumem papeis heterossexuais, escondendo o desejo, ou a prática sexual homoerótica, às vezes já descobertas na infância. $\mathrm{O}$ que nos sugere que tanto a questão de esconder a sua sexualidade, dificulta a percepção des passarofes, quanto a falta de conhecimento sobre a temática em questão, podem explicar o dito e não-dito nas entrevistas.

Então, colocamos uma pergunta mais impactante, que movesse a resposta para o lado pessoal. Pois a teoria e os acontecimentos com es outres são mais fáceis de quando acontece na nossa família com conosco. Desta maneira a pergunta que se destacou foi: E se fosse sua filha ou filho?

Bem-te-vi respondeu dessa maneira: como eu te falei né, é uma situação de situação o que me resta é aceitar[...] primeiramente não é uma coisa que se espere ou que se aceite [...]. Ressaltou que geralmente as pessoas tem mais facilidade de aceitar quando é com a família do outro, quando é na sua família, geralmente tem uma reação um pouco diferente. "a minha opinião seria de aceitação". Quando perguntando o que ele poderia falar para o filho, respondeu: que há muita discriminação e preconceito, mas não restaria outra saída é a não ser apoiar. Acho que a felicidade pode está relacionada com a escolha sexual. Depois repetiu a palavra aceitação e a conversa mais uma vez, afirmando que não teria como ser diferente. "A felicidade está muito relacionado com isso" [...] então o respeito e a tolerância e claro essa 
questão de saúde, tem toda essa relação com os cuidados da saúde e conscientização das dificuldades".

Com o Sabiá a resposta foi a seguinte:

é complicado, acho que o estranhamento seria normal[...] mas aceitaria, não teria porque recusar né, a opção dele ou dela[...] Ele pensa em ter filhos[...]eu acho tão bonita menina, pra ser filha". "se ela quisesse ter uma relação com uma menina também não teria problema.

Andorinha ressaltou que iria orientar a filha, se caso fosse, mas não se prolongou muito, relatou inclusive que talvez o marido tivesse mais resistência. Já Trinca-Ferro, expressou uma reflexão mais elaborada:

\begin{abstract}
"eu acho que na verdade, se eu tivesse alguma insatisfação, seria de não ter neto, né, por que daí...até meu mais velho sempre fala que vai adotar...não ia mudar com eles ia ser maior amor, tanto pra eles quanto pro namorado né, eu acho, eu acho(gaguejou) que conseguiria ser assim, mas eu acho que eu não ia ser feliz como eu sou hoje, eu acho que eu ia querer que meus filhos me dessem um neto e aquela cultura, que eu acho na verdade idiota, mas tá enraigada(enraizada), ...a gente ensinado desde pequenininho que é papai, mamãe e filhinho, então, é uma coisa assim, que, mas, eu, eu sempre me acostumei com qualquer coisa, eu me acostumei que eu fui embora morar no Paraguai, pra, pra, pra, pra minha, pro um jeito que eu pensava, era extrema, pros últimos dos últimos que ia morar pra lá, era pra quem era pobre, palpérrimo, sabe, a crendice, do jeito que fui criada, e fui sobrevivi, se quer saber, eu tenho saudade, eles tratam a gente com carinho com respeito.
\end{abstract}

A Beija-Flor revelou que já havia pensado na possibilidade, mas que teria todo o seus apoio, respondendo que: "quero que meus filhos sejam felizes". Apenas lembrando que seu marido teria mais resistência "Eu acho que teria mais um pouco mais né, por questão da formação mesmo, ele não é machista nada, mas teria talvez que trabalha mais um pouquinho com ele, com a cabeça dele, mas também não teria grandes dificuldades”.

Quero-Quero afirmou que não teria problema algum, mas que precisaria estuar mais sobre o assunto: "eu teria que ter uma base", mas que não tinha nenhum receio particular [...] "eu ainda vejo que é uma...acho que carrega consigo, de nascença, vamos se dizer assim, alguns dizem que é uma doença que pode ser curado... eu vejo que a gente sem uma certa autonomia como administrar. E com respostas mais curtas, Canarinha disse que não saberia e não voltou mais ao assunto.

Sendo assim, a maioria se mostrou solícito a tentar entender, então, foi es passarofes foram fomentades a responderem com sinceridade se eles de fato achavam essa pesquisa importante. 


\section{CONSIDERAÇÕES FINAIS}

Compreendemos que as questões identitárias dependem da subjetividade, do tempo e do espaço que esta subjetividade se encontra em processo de construção, além das hierarquias de privilégios e desprivilegio existentes nos sistemas educacionais, nas relações interpressoais e intrapessoais, assim como nas construções culturais que permeiam no dito e não dito, nas adubações e inadubações da terra que existem em nossos corpos e como também passarinhes, nos utilizamos da mesma, ou de nós mesmos.

Passarofes todos os dias seja dentro ou fora da escola, possuem desafios, sobretudo, em uma escola do campo, que por si só é uma resistência aos discursos de poder e dispositivos que a marginalizam, começam assim, a criar suas próprias maneiras de ser e estar no mundo, e ainda, sua escolarização, suas culturas e suas maneiras de educar, a partir da valorização do trabalho na terra e seus silêncios do campo, demonstram organização coletiva, entretanto, não estão fora das ondas heteronormativas, patriarcalistas e misóginas que a globalização nos aprisiona.

É fato, que infelizmente es passarofes pesquisades possuem diversas dúvidas sobre o como agir em relação a temática, ou mesmo se uma aluna que se enquadre neste rótulo lesbiano posso a vir lhes pedir ajuda. E, mesmo, a questão do medo da reação dos pais, ou como um "problema" a ser resolvido pela direção ou coordenação da escola. Entretanto, mesmo com receios e dúvidas, a maioria mostrou-se disposto a tentar ajudar a passarune que talvez pudesse vir lhe procurar.

Neste sentido, mesmo com as torres panópticas vigilantes e controladoras, mais forte que este sistema, é a intenção de educação e bem estar, na missão que esses passarofes tentam todos os dias desenvolver minimamente, na vivência estudantil dessas e desses passarunes do campo.

\section{REFERÊNCIAS}

BEAUVOIR. Moral da Ambigüidade. Trad. Marcelo Jacques de Moraes, RJ: Nova Fronteira, 2005.

BENTHAM, Jeremy. [et al.]. O Panóptico. organização de Tomaz Tadeu; traduções de Guacira Lopes Louro, M. D. Magno, Tomaz Tadeu. 2. ed. Belo Horizonte: Autêntica Editora, 2008.

BERNARDI, Marcello. A deseducação sexual. São Paulo: Summus, 1985. 
BRASIL, Novo Ensino Médio - DÚVIDAS. Profissionais com notório saber poderão dar aula na parte comum do currículo? Como será a formação de professores? Brasília: MEC, 2016. Disponível em: <http://portal.mec.gov.br/publicacoes-para-professores/30000uncategorised/40361-novo-ensino-medio-duvidas > Acessado em: 27/08/2016.

BUTLER, Judith. Corpos que Pensam: Sobre os Limites Discursivos do Sexo. In: O Corpo Educado: Pedagogias da Sexualidade. Tomaz Tadeu da Silva (Trad.) 2 e., p. 126-151, Belo Horizonte: Autêntica, 2001.

FAUR, Mirella. O Anuário da Grande Mãe: guia prático de rituais para celebrar a Deusa. 2 ed. São Paulo: Gaia, 2001.

FITZ, Ricardo Arthur. Os Jesuítas no território Gaúcho. In: Releituras das História do Rio Grande do Sul. Instituto Gaúcho de Tradição e Folclore. Organizadores: Sandra da Silva Careli, Luiz Claudio Knierim. Porto Alegre-RS: CORAG, 2011. p.43-64.

FOUCAULT, Michel. A Ordem do Discurso: aula inaugural no College D'e France, pronunciada em 2 de dezembro de 1970. Trad. Laura Fraga de Almeida Sampaio, São Paulo: Edições Loyola, 2014.

A Hermenêutica do Sujeito. Michel Foucault: edição estabelecida sob a direção de François Ewald e Alessandro Fontana, por Frédéric Gros ; tradução: Márcio Alves da Fonseca. Salma Tannus Muchail. - 2ºd. - São Paulo: Martins Fontes, 2006.

História da Sexualidade I: a vontade de saber. Trad. M.T.C. Albuquerque e J. A G. Albuquerque. Rio de Janeiro: Graal, 1988.

. História da Sexualidade III: o cuidado de si. Trad. Maria. Tereza. C. Albuquerque e Ver. técnica de José. A G. Albuquerque. Rio de Janeiro: Graal, 1985.

Michel Foucault, Uma Entrevista: sexo, poder e a política da identidade. verve, 5: 260-277, 2004. Disponível em: 〈https://revistas.pucsp.br/index.php/verve/article/viewFile/4995/3537> Acesso em: 20/11/2015.

A arqueologia do saber; tradução de Luiz Felipe Baeta Neves, -7ed. Rio de Janeiro: Forense Universitária, 2008.

Petrópolis/RJ: Vozes, 1987.

Vigiar e Punir: nascimento da prisão. Trad. Lígia M. Ponde Vassalo.

GIROUX, Henry. Professores como Intelectuais Transformadores. In: Os professores como Intelectuais: rumo a uma pedagogia crítica da aprendizagem. Porto Alegre: Artes Médicas, 1997, p. 157-164.

GUIMARÃES, Isaura. Educação Sexual na Escola: mito ou realidade. Campinas, SP: Mercado de Letras, 1995 (Coleção Dimensões da Sexualidade). 
JACONDINO, E. Nunes. Sobre o Corpo: Epistemologia, Identidade, Educação, Cultura. Cascavel/PR: UNIOESTE, 2006.

JESUS, Jaqueline Gomes de. Identidade de gênero e políticas de afirmação identitária. In: ABEH. Congresso Internacional de Estudos sobre a Diversidade Sexual e de Gênero. Salvador, 2012.

LAU, Héliton Diego. Pelo direito e orgulho de ser heterossexual no terceiro domingo de dezembro: os discursos de Carlos Apolinário e Eduardo Cunha nos PLs 294/2005 e 1672/2011. 2016. 174 f. Dissertação (Mestrado em Linguagem, Identidade e Subjetividade) Universidade Estadual de Ponta Grossa-UEPG, Ponta Grossa-PR, 2016.

LUCKESI, Cipriano Carlos. Filosofia da Educação. São Paulo: Cortez, 1994.

MELO, Sonia M. M. de. Corpos no Espelho: A Percepção da Corporeidade em Professoras. Campinas, SP: Mercado de Letras, 2004.

PALMA, Yáskara A.; LEVANDOWSKI, Daniela C. Vivências Pessoais e Familiares de Homossexuais Femininas. Biblioteca Virtual em Saúde, Rev Psicologia em Estudo v.13 n.4. Universidade Estadual de Maringá, dezembro de 2008. Disponível em: <http://www.scielo.br/scielo.php?script=sci_arttext\&pid=S1413-

73722008000400015\&lng=pt\&nrm=iso $>$ Acesso em: 06/09/2013.

PIASON, Aline da S. Mulheres Que Amam Mulheres: Trajetórias de Vida, Reconhecimento e Visibilidade Social ás Lésbicas. Biblioteca Digital de Teses e Dissertações, Mestrado em Psicologia Social, PUC RS: 2008. Disponível em: <http://tede.pucrs.br/tde busca/arquivo.php?codArquivo=1981> Acesso em: 19/03/2013.

PPGED. Linha de Pesquisa: Processos Educativos (Programa de Mestrado). UNIVERSIDADE DO OESTE DE SANTA CATARINA, 2016. Disponível em: $<$ http://www.unoesc.edu.br/images/uploads/mestrado/Processos_Educativos.pdf $>$ Acesso em: $18 / 05 / 2016$.

PSICOLOGIA, Conselho Federal. Resolução 001/99. Código de Ética do Psicólogo, Brasília, 22 de março de 1999. Disponível em: <http://site.cfp.org.br/wpcontent/uploads/1999/03/resolucao1999_1.pdf>

SILVA. Tomas Tadeu da. Identidade e Diferença. A perspectiva dos estudos culturais. Petrópolis/RJ: Vozes, 2003.

VEIGA-NETO, Alfredo. Foucault \& a Educação. 2 ed. Belo Horizonte: Autêntica, 2007. 